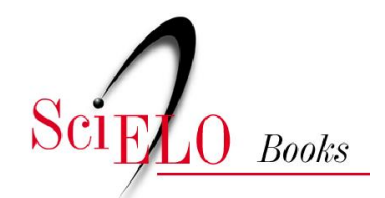

\title{
A reflexividade no saber leigo sobre as práticas alimentares
}

\author{
Christiane Ayumi Kuwae \\ Luisa Ferreira Silva \\ Maria Cláudia da Veiga Soares Carvalho \\ Francisco Ferreira Romão \\ Cristina Maria Lopes Pereira Vieira \\ Shirley Donizete Prado
}

\section{SciELO Books / SciELO Livros / SciELO Libros}

KUWAE, CA., et al. A reflexividade no saber leigo sobre as práticas alimentares. In: PRADO, SD., et al. orgs. Estudos socioculturais em alimentação e saúde: saberes em rede. [online]. Rio de Janeiro: EDUERJ, 2016. Sabor metrópole series, vol. 5, pp. 33-57. ISBN: 978-85-7511-456-8. Available from: doi: $10.7476 / 9788575114568$. Also available in ePUB from: http://books.scielo.org/id/37nz2/epub/prado-9788575114568.epub

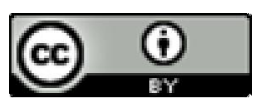

All the contents of this work, except where otherwise noted, is licensed under a Creative Commons Attribution 4.0 International license.

Todo o conteúdo deste trabalho, exceto quando houver ressalva, é publicado sob a licença Creative Commons Atribição 4.0.

Todo el contenido de esta obra, excepto donde se indique lo contrario, está bajo licencia de la licencia $\underline{\text { Creative Commons }}$ Reconocimento 4.0. 


\title{
A reflexividade no saber leigo sobre as práticas alimentares ${ }^{1,2,3}$
}

\author{
Christiane Ayumi Kuwae \\ Luisa Ferreira Silva \\ Maria Cláudia da Veiga Soares Carvalho \\ Francisco Ferreira Romão \\ Cristina Maria Lopes Pereira Vieira \\ Shirley Donizete Prado
}

\section{Introdução}

As pesquisas sobre alimentação na área da saúde tendem a conceber essa dimensão da vida do homem como uma ação natural, de viés biologicista e com predomínio do pensamento biomédico. No entanto, ao aprofundarmos as pesquisas sobre alimentação, torna-se evidente quanto esse é um aspecto da vida social mediado pela cultura e influenciado pelos diversos contextos.

Ao mesmo tempo que a alimentação é uma necessidade biológica, da ordem da natureza, é organizada segundo critérios sociais, os quais, por sua vez,

1 Este capítulo corresponde à parte teórica da tese de doutorado de Christiane Ayumi Kuwae, em desenvolvimento no Programa de Pós-Graduação em Alimentação, Nutrição e Saúde do Instituto de Nutrição da Universidade do Estado do Rio de Janeiro.

2 Este trabalho é desenvolvido com financiamento proveniente de uma bolsa de doutorado da Fundação de Amparo à Pesquisa do Estado do Rio de Janeiro (Faperj) e da bolsa de doutorado sanduíche da Coordenação de Aperfeiçoamento de Pessoal de Nível Superior (Capes) - Proc. n. 99999.007200/2014-05. O estágio no exterior foi realizado na Universidade de Lisboa, sob a supervisão da Profa. Luisa Ferreira Silva.

3 O texto mantém a redação própria de cada autor(a), não fazendo harmonização de estilo entre o português do Brasil e o de Portugal. 
são influenciados pelas relações sociais (Mennel et al., 1992). O que é bom para comer modifica-se ao longo da história, dos grupos, das religiōes, dos interesses econômicos ou dos critérios que classificam a comida, como, por exemplo, a alimentação saudável. Diversos estudos apontam para o carácter plural do que pode ser compreendido como saudável (Lupton e Chapman, 1995; Silva, 2006; Kuwae et al., 2015; Cavalcante et al., 2015). Nesse sentido, as definições do que é comestível ou bom para comer são também classificações sociais que se (re) organizam nas relações entre os sujeitos e deles com as instituições, meios de produção e consumo e seus significados culturais (Mintz, 2001).

A aproximação das ciências humanas e sociais (principalmente da sociologia e da antropologia) com os estudos da alimentação evidencia os vários aspectos da alimentação construídos nas relações sociais. A compreensão mais aprofundada da alimentação de um indivíduo é atravessada pelas formas de organização da comida de um grupo, do que se tem disponível para consumir, dos valores simbólicos da alimentação; portanto, faz-se necessário olhar para essa relação entre indivíduo e sociedade presente também na alimentação. Nessa relação, é possível pensar em critérios e valores subjetivos da ordem da cultura, da religiosidade, da ideologia e dos modismos; mas também existem critérios e valores objetivos para se pensar a comida, como, por exemplo, preço, capacidade de produção e distribuição, interesses econômicos das empresas transnacionais, da indústria de alimentos etc.

$\mathrm{Na}$ atualidade, a comida é uma mercadoria de valor econômico em escala global, resultado do movimento do capitalismo de fusão entre empresas, expansão dos mercados em desenvolvimento, ampliação da capilaridade de distribuição, padronização dos produtos e planificação dos negócios. A intensa transformação nas formas de produção de bens, o avanço tecnológico, a intensificação do comércio mundial, a diversificação dos meios de comunicação e a crescente circulação de bens, pessoas e mensagens pelo mundo levaram à modificação nos modos de vida dos últimos anos, incluída a alimentação (Contreras e Gracia, 2011). Tais modificações foram contextuais, no sentido do que se tem disponível para o consumo alimentar, mas também pertencem à ordem simbólica, como, por exemplo, o que é considerado bom para se comer.

Nesse sentido, as mudanças observadas nas práticas alimentares dos últimos anos não são passivas nem simplesmente adaptativas à multiplicidade dos novos alimentos, mas um ato pleno de significado. Uma nova comida 
só é aceita quando assimilada dentro do modo de organização alimentar do sujeito (do grupo, da comunidade); dessa forma, a incorporação de um novo alimento também é um processo de ressignificação nas práticas alimentares dos sujeitos (Cancline, 2007; Contreras e Gracia, 2011). E esse processo de ressignificação é provocado, em grande parte, pelo interesse da indústria, que "lança novos produtos" ou ressignifica os produtos tradicionais com um bom potencial de vendas, como, por exemplo, as linhas diet, light e natural, vendidas sob o rótulo de "alimento saudável". O que importa é a imagem - o conceito de saudável ou de gourmet que ajuda a aumentar as vendas.

A alimentação é cada vez mais interceptada pelos novos produtos alimentares e por novas normas que reorganizam e ressignificam a alimentação contemporânea, em razão: da multiplicação da variedade de alimentos disponíveis para consumo, proporcionada pela melhora na produção de alimentos e pelo comércio globalizado; da dinâmica do consumismo e de seu imperativo de inovação (Fischler, 1995; Freire et al., 2014); dos diversos modos de organizar a alimentação, segundo novos critérios ecológicos, morais, estéticos ou políticos, como a alimentação orgânica, vegetariana, vegana, os alimentos funcionais, as dietas da moda, entre tantos outros estilos alimentares (Costa et al., 2013; Carvalho e Sabino, 2013); dos diversos riscos trazidos pela inovação científica, tanto dos alimentos transgênicos quanto dos efeitos da contaminação por agrotóxicos, das novas descobertas de elementos e substâncias químicas presentes nos alimentos antes desconhecidos (Galindo e Portilho, 2013). A isso, acrescem-se o maior apelo à racionalidade científica sobre o comer, presente nos discursos de especialistas, como nutricionistas, associações médicas e nutrólogos, e a vulgarização desse conhecimento (nem sempre correto) pela mídia, em programas televisivos, websites e inúmeras revistas sobre comida (Ferreira et al., 2013).

Essa multiplicidade de critérios para organizar a alimentação e a crescente variedade de alimentos disponíveis modificam as práticas alimentares, pois exigem dos sujeitos uma constante reelaboração do que comer. Segundo Fischler (1995), essa "cacofonia alimentar" seria reflexo de uma polifonia dietética, ou seja, a multiplicação de agentes e de discursos alimentares acaba por confundir o sujeito, gerando práticas alimentares desorganizadas e até mesmo contraditórias. Talvez seja mais assertivo afirmar que tal cenário retira a alimentação de uma prática naturalizada no cotidiano, que seguia uma normatividade cristalizada como uma rotina, marcando a descontinuidade de 
um savoir-faire. Agora, o comensal tem de escolher constantemente como se alimentar. Nesse sentido, a alimentação tenderia a ser uma atividade cotidiana cada vez mais reflexiva (Azevedo, 2008; Fischler, 1995). Critérios como "racionalidade da escolha", "produção politicamente correta”, "comprovação científica”, "produção sob condiçōes de sustentabilidade”, "produção a partir de normas rígidas de segurança” e outros clichês utilizados pelas agências de propaganda dão o tom dessa nova comensalidade, baseada na "escolha racional por evidências científicas".

Esse apelo a uma reflexividade sobre a escolha alimentar está imerso numa modernidade reflexiva que é indissociável da questão do risco, pois a sociedade antecipa e pensa a partir do risco, e ele aparece quando ocorre uma tomada de decisão política e/ou econômica, constituindo a primeira decisão em se definir o que comporta ou não risco (Gardner, 2009). Apresentar os riscos à atenção pública e à agenda política, hierarquizar esses riscos, fechar os olhos para determinado risco, decidir corrê-lo ou não ou partilhar os riscos, tudo isso é objeto de atenção pública, debates e negociações. A obesidade aparece hoje como o inimigo número um, e os riscos e as consequências que ela apresenta são alardeados como algo insustentável para as sociedades no longo prazo, em face dos custos para a previdência social e a seguridade social (Castiel, 2010). Qualquer risco implica custo.

Nenhuma nação, nenhuma classe social e nenhum grupo social estão protegidos nessa lógica dos riscos, envolvendo todos os componentes da sociedade para além das fronteiras ou das gerações. Desse modo, os riscos afetam os limites do tempo, na medida em que o presente é menos determinado pelo passado do que por uma projeção do futuro, pelas hipóteses consideradas em relação a um futuro abstrato. O futuro é continuamente trazido para o presente por meio das organizações reflexivas dos ambientes de conhecimento, afetando também a noção de espaço, pois os riscos ultrapassam fronteiras, e os novos riscos são, simultaneamente, globais e locais (Gardner, 2009; Beck, 2011).

A modernidade altera, de forma radical, a natureza da vida social cotidiana, afetando os aspectos mais pessoais de nossa existência, pois as transformações trazidas pelas instituições modernas se entrelaçam, de maneira direta, com a vida individual e, portanto, com o Eu. Desse modo, é crescente a interconexão entre os dois extremos da extensão e da intencionalidade: influências globalizantes de um lado e disposições pessoais do outro. 
A autoidentidade se torna um empreendimento reflexivamente organizado, e a noção de estilo de vida assume um significado particular, direcionado por influências padronizadoras, em sintonia com o mundo do consumo, pois a produção e a circulação de mercadorias são componentes centrais das instituições da modernidade (Giddens, 2002). A reflexividade, portanto, caminha lado a lado com as transformações sugeridas pelo mercado e pelos grandes meios de comunicação, colocando em relação interesses distintos e antagônicos, que se apresentam como naturais e universais. São jogos de poder que se viabilizam pelos discursos dos atores sociais em cena; porém, o peso político dos atores nem sempre é igual - muito pelo contrário.

No cenário contemporâneo, o jogo de poder acontece de modo mais complexo. O Estado e o sistema político fazem parte de um sistema de poder que se articula com outras forças importantes, como o mercado e os sistemas de comunicação (Giddens, 2003). O Estado não impõe sua força sobre o conjunto da sociedade; ele negocia e apenas arbitra os interesses colocados em jogo pelo capitalismo global. Trata-se de forças econômicas que ultrapassam o que conhecemos como Estado e chamávamos de nação, pois o poder de ampliar ou retirar os investimentos muitas vezes está acima e à margem dos interesses da coletividade e de uma possibilidade de reflexividade no nível individual ou local.

As grandes instituições, como o mercado e o Estado, apoiam-se na ciência (econômica, política e jurídica), e cada uma delas constitui o modelo exclusivo em seu próprio setor, produzindo um discurso racional, eficaz, sem falhas e aparentemente neutro. A qualidade dos alimentos, então, é apresentada como uma evidência científica inquestionável. Desse modo, a ciência contemporânea se apoia na criação de uma linguagem específica e própria, distante da linguagem cotidiana, produzindo afastamento dos dados qualitativos, sociais e emotivos dos alimentos, a fim de valorizar apenas seus aspectos quantitativos, racionais, objetivos e relacionais.

O senso comum, por outro lado, ao ignorar as relações complexas entre as teorias científicas e as técnicas, tende a identificar as ciências com o resultado de suas aplicaçôes, produzindo a crença infundada de que a ciência pode e deve conhecer tudo; que, de fato, conhece tudo, e é a explicação causal das leis da realidade tal como esta é em si mesma. Tal cientificismo se apresenta também na indústria de alimentos, que fomenta essa crença no progresso e na evolução de conhecimentos que, um dia, explicarão a realida- 
de na íntegra e permitirão manipulá-la tecnicamente, sem limites para a ação humana (Chauí, 2000), produzindo um alimento perfeito, com zero caloria, revestido de puro prazer.

Essa crença na ciência como se fosse magia, dando-lhe o lugar que muitos costumam atribuir às religiões - ou seja, de um conjunto doutrinário de verdades atemporais, absolutas e inquestionáveis -, precisa ser pensada à luz da reflexividade proposta por Giddens (2000). Essa noção não leva em conta a existência de uma razão instrumental que age nos corações e nas mentes, transformando a ciência em ideologia e mito social, ou seja, em senso comum cientificista; transformando a teoria científica em ideologia, ao utilizar o discurso científico como instrumento de dominação, controle e poder sobre a natureza e a sociedade.

$\mathrm{Na}$ teoria da reflexividade, existe a afirmação de que a própria razão questiona suas próprias pretensões e seus próprios fundamentos. Ela produz uma autoanálise permanente, tanto para os indivíduos como para os grupos, transformando a relação de cada um consigo e com o mundo na vida diária.

É no sentido de aprofundar conceitualmente tal análise que, neste artigo, apresenta-se uma revisão do conceito de reflexividade nas teorias sociais de seus principais autores, como as desenvolvidas por Anthony Giddens, Ulrich Beck e Margaret Archer. Pela mediação entre sistema e indivíduo, implícita no conceito de reflexividade, a revisão que se faz sobre o conceito é alargada para a teoria interacionista e a teoria construtivista que Pierre Bourdieu desenvolveu sobre o habitus, posteriormente aprofundada por Bernard Lahire. Nessa direção, pretende-se, aqui, apresentar tal conceito conforme a abordagem desses autores, na medida em que podem contribuir para as pesquisas no campo da alimentação.

\section{Anthony Giddens: teoria da estruturação}

Anthony Giddens propõe a teoria da estruturação como forma de análise da relação entre estrutura e agência, demonstrando que ambas estão intrinsecamente relacionadas nas ações sociais, constituindo uma autêntica dualidade.

A constituição de agentes e estruturas não são dois conjuntos de fenômenos dados independentemente - um dualismo -, mas representam uma dualida- 
de. De acordo com a noção de dualidade da estrutura, as propriedades estruturais de sistemas sociais são, ao mesmo tempo, meio e fim das práticas que recursivamente organizam (Giddens, 2003, p. 30).

Dessa forma, a estrutura é, ao mesmo tempo, um meio de constrangimento e de possibilidade da agência, sendo definida como um conjunto de regras e recursos que são acionados no curso da ação. As regras podem ser tanto normativas como interpretativas, enquanto os recursos podem ser alocativos ou impositivos (Giddens, 2003). Para esse autor, a estrutura conta com uma ordem virtual que só pode ser concretizada na ação, pois é nesse momento que a estrutura se torna manifesta. Antes da ação, a estrutura estaria presente como as propriedades estruturais que orientam a ação. No entanto, a estrutura não é determinística da ação do sujeito, pois está presente na forma de princípios estruturais (traços de memória), os quais são acionados no decorrer da ação social (Giddens, 2003).

A agência, ou capacidade do ser humano de conhecer e de agir sobre seu contexto, mesmo que essa ação nem sempre seja consciente, caracteriza-se por três atributos: racionalidade, reflexividade e intenção. A racionalidade significa que não se trata de um mero ato mecânico ou reprodutivo, mas de "um contínuo entendimento teórico das bases da sua actividade" (Giddens, 2003, p. 4). A reflexividade diz respeito à capacidade dos indivíduos de serem sujeitos e objetos de sua própria vida. E, por fim, a intencionalidade clarifica que, apesar de a ação ser direcionada a um objetivo, há elementos da intencionalidade que não são premeditados pelo sujeito (Giddens, 2003).

Ao longo de seu trabalho, Giddens apresenta a reflexividade em dois níveis distintos nas três obras analisadas neste trabalho. No livro $A$ constituição da sociedade, a reflexividade é apresentada como uma capacidade humana presente na relação com o outro, como uma automonitoração da própria ação e da reação do outro nos contextos de interação social, como um meio de mediar as relações sociais. Nas palavras do autor:

A "reflexividade" deve ser entendida não meramente como "autoconsciência", mas como o caráter monitorado do fluxo contínuo da vida social. Assim, é útil falar de reflexividade como algo assentado na monitoração contínua da ação que os seres humanos exibem, esperando o mesmo dos outros. A monitoração reflexiva da ação depende da racionalização, entendida aqui mais 
como um processo do que como um estado, e como inerentemente envolvida na competência dos agentes (Giddens, 2003, p. 3).

Segundo essa acepção, a reflexividade faz parte do cotidiano dos sujeitos, embora estes nem sempre estejam aptos a explicitá-la de forma organizada em seu discurso. Está presente como um modo de organização do cotidiano, de uma forma praxiológica ou, como o autor denomina, mais como uma consciência prática do que propriamente uma ação racionalizada ou consciente:

As capacidades reflexivas do ator humano estão caracteristicamente envolvidas, de modo contínuo, no fluxo da conduta cotidiana, nos contextos da atividade social. Mas a reflexividade opera apenas parcialmente num nível discursivo. O que os agentes sabem acerca do que fazem e de por que o fazem - sua cognoscitividade como agentes está largamente contida na consciência prática. Esta consiste em todas as coisas que os atores conhecem tacitamente sobre como "continuar" nos contextos da vida social sem ser capazes de lhes dar uma expressão discursiva direta (Giddens, 2003, p. XXV).

No livro A transformação da intimidade: sexualidade, amor e erotismo nas sociedades modernas, Giddens argumenta como a reflexividade institucional (penetração da sociedade pelo conhecimento e vice-versa) engrena mudanças nas práticas individuais ou dos grupos. $\mathrm{O}$ autor busca esclarecer como as mudanças na forma de compreender determinado tema (no caso do livro, a sexualidade) a partir de pesquisas científicas e da respectiva divulgação pelas mídias modificam as práticas dos sujeitos por meio de uma apropriação reflexiva. Nas palavras do autor:

Desde que há uma nova terminologia para se compreender a sexualidade, as ideias, os conceitos e as teorias expressos nesses termos penetram a própria vida social e ajudam a reordená-la. Para Foucault, no entanto, esse processo surge como uma intrusão determinada e direta do "poder-conhecimento" na organização social. Sem negar a sua conexão com o poder, devemos considerá-lo mais como um fenômeno de reflexividade institucional em constante movimento. É institucional por ser o elemento estrutural básico da atividade social nos ambientes modernos. É reflexivo no sentido de que os termos 
introduzidos para descrever a vida social habitualmente chegam e a transformam - não como um processo mecânico, nem necessariamente de uma maneira controlada, mas porque se tornam parte das formas de ação adotadas pelos indivíduos ou pelos grupos (Giddens, 1993, p. 39).

Dessa forma, Giddens busca elucidar como um novo vocabulário proposto pelas instituiçóes para se compreender uma prática (e as ideias, os conceitos e as teorias expressas nesses novos termos) pode reordenar as práticas "leigas", por fornecer novos critérios de organização e de compreensão dessas práticas. $\mathrm{O}$ autor argumenta que as pesquisas sobre sexualidade, sua divulgação e os debates que surgem de acordo com esse novo enfoque provocam mudança na maneira como os sujeitos percebem e significam suas práticas. De forma análoga, é possível refletir que, no campo da alimentação, as pesquisas sobre nutrição produzem um novo modo de organizar a alimentação, divulgado em forma de recomendações nutricionais ou apropriadas pela indústria alimentar, e introduzem outra forma de se compreender e organizar a alimentação dos sujeitos em sua prática cotidiana.

Giddens também defende que a reflexividade institucional é característica das sociedades modernas, pelas questôes ligadas à globalização e porque "a contínua incorporação reflexiva do conhecimento não apenas se introduz na brecha; ela proporciona precisamente um ímpeto básico às mudanças que ocorrem nos contextos pessoais, e também globais, da ação" (1993, p. 40). Dessa forma, ele coloca a reflexividade como um conceito que expressa a dualidade da estrutura, ao mesmo tempo que é o mote e o meio que provoca mudança nas práticas das sociedades modernas.

Nesse sentido, Giddens também argumenta que, "hoje em dia, o eu é para todos um projeto reflexivo - uma interpretação mais ou menos contínua do passado, do presente e do futuro (1993, p. 41). E, segundo esse imperativo de construção permanente da autoindentidade, a reflexividade do corpo estaria ligada à noção moderna de dieta, em que é preciso ter disciplina e conhecimento, uma responsabilização do sujeito por seu estilo de vida.

No livro Modernidade reflexiva, Giddens apresenta a reflexividade em um nível mais sistêmico, no sentido de que, na modernidade tardia, o conhecimento e a reflexividade estão no cerne das mudanças sociais, que se caracterizam pelo centramento na noção de risco, a qual, por sua vez, advém do aumento de conhecimento. 
Em contextos pós-tradicionais, não temos outra escolha para além de escolher como ser e como actuar. Desde esta perspectiva, até as dependências são escolhas: são modos de lidar com a multiplicidade de possibilidades oferecidas por praticamente todos os aspectos da vida quotidiana quando se vê de maneira adequada (Giddens, 2000, p. 72).

\section{Beck: a modernização reflexiva}

Para Ulrich Beck, o conceito de "modernização reflexiva" surge associado ao de "autoconfrontação", implicado nas consequências dos processos de modernização autonomizada, que emergem indiferentes às ameaças latentes da sociedade de risco. É nesse contexto de confrontação entre a estrutura da modernização e suas consequências que surge a reflexividade.

A sociedade de risco traz a transformação de diferentes sistemas de referência da sociedade industrial e abala alguns dos princípios fundamentais da organização social (como, por exemplo, os papéis de gênero e o desencanto nas fontes de significado do progresso ou na consciência de classe). Ou seja, ao recurso das velhas formas lineares de organização social da sociedade industrial, contrapôe-se "a nova desordem da sociedade de risco" (Beck, 2000, p. 12).

A perda das várias proveniências de significado determina, a todo custo, um esforço de definição do indivíduo. Num contexto em que prevalecem não um, mas vários modelos de modos de vida e várias opções que estão presas ao outro(s), o indivíduo da modernidade "ambivalente" é simultaneamente confrontado com uma variedade de riscos. Em conjunto com o alargamento da educação, a confrontação permite ao indivíduo ser sujeito de sua própria percepção, significação e gestão das "oportunidades arriscadas". Levando em conta a complexidade da sociedade moderna, a gestão dessas "oportunidades" não é feita sob tomadas de decisão sólidas e responsáveis, como seria a gestão das expectativas do passado; ela é cada vez mais orientada e percebida por cada um, em função das prováveis consequências "arriscadas". A imprevisibilidade das ameaças gera a necessidade de autorreflexão: "No autoconceito de sociedade do risco, a sociedade torna-se reflexiva (no sentido mais estrito da palavra), o que equivale a dizer que se torna um tema e um problema em si mesmo" (Beck, 2000, p. 8).

O autor adverte para o fato de que "o risco" implica a especificidade cultural no contexto de uma sociedade pluralista, ou seja, pensar o risco exige 
levar em conta as diferentes decisões e os pontos de vista que cada indivíduo usa para avaliá-las.

\section{Margaret Archer: teoria do realismo social}

Em 1982, Margaret Archer apresentou sua abordagem morfogenética, que, mais tarde, viria a renomear como "teoria do realismo social". A realidade social existe independentemente do indivíduo, e os agentes atuam de acordo com as circunstâncias estruturais e culturais que suas próprias açóes contribuem para modificar ou para reproduzir (Porpora, 2013). Nessa abordagem, ela se afasta da teoria da estruturação de Giddens, a que critica a "superssocialização" dos agentes pela interiorização de sua condição social, num modelo teórico que oscila entre determinismo e voluntarismo (King, 2010).

Segundo a autora, a relação entre agência e estrutura pode ser analisada esquematicamente segundo a "sequência morfogenética básica", composta de três fases: condicionantes estruturais, interação social e elaboração da estrutura. Ou seja, a interação social acontece segundo as condicionantes estruturais (que são condicionantes, e não determinísticas) e resulta na reprodução da estrutura (fatores morfoestáticos) ou em sua modificação (fatores morfogenéticos). Ao completar esse ciclo morfogenético com a (re)elaboração estrutural, tanto a estrutura como a agência são modificadas, resultando, assim, em uma dupla morfogênese. As condicionantes estruturais não são determinísticas justamente porque são mediadas pelo sujeito através de sua agência, numa relação que se processa pela reflexividade, ou seja, a capacidade do sujeito de compreender e elaborar sua ação (Archer, 1995).

A autora considera que, para que algum fator seja condicionante (tanto em termos estruturais como culturais), dependeria de três características: dos projetos do sujeito, da relação entre os projetos e as condicionalidades, bem como da reação dos sujeitos a essas condicionantes, de acordo com seus projetos. Ressalta-se que tais deliberações são de natureza reflexiva e incluiriam as habilidades de se resistir a elas ou driblá-las (Archer, 2011).

Em outras palavras, para que qualquer coisa possa exercer o poder contingente de um constrangimento ou de um incentivo, precisa figurar em uma relação de tal modo que obstrua ou facilite a consecução de uma empreitada agêntica específica, conforme subjetivamente definida (Archer, 2011, p. 165). 
A reflexividade acontece no espaço das "conversaçôes internas", como um espaço de mediação entre o self e o mundo exterior. Essa noção de conversação interna traduz a capacidade do sujeito de se tomar, ao mesmo tempo, como sujeito e objeto de si mesmo, portanto reflexivo sobre si mesmo. A conversação interna apresenta três características principais: é um diálogo interior, mental, portanto não é diretamente observável; tem uma ontologia subjetiva, pois é privativa do sujeito; e tem eficiência causal, pois é capaz de modificar a ação do sujeito. Segundo a análise de Ana Caetano sobre esse conceito,

os diálogos internos ocorrem, de acordo com a autora, em três fases que compõem o esquema dialógico da agência humana: discernimento, deliberação e dedicação. Os sujeitos procuram discernir cursos de acção possíveis, deliberam sobre as implicaçôes (vantagens e desvantagens) de cada uma dessas condutas e tomam uma decisão com base no balanço mental das etapas prévias. Ao mesmo tempo, estas decisões podem sempre ser reformuladas (Caetano, 2013, p. 77).

Colocando a reflexividade como mediação entre estrutura e agência, Archer diferencia o peso da reflexividade na agência do sujeito. A ação é codeterminada pela reflexividade e as disposições, em contribuições variáveis, podendo ter mais ou menos importância na agência, de acordo com as formas de conhecimento (incorporado, prático e discursivo) e suas ordens da realidade (natural, prática e social) (Archer, 2011).

Archer defende que a socialização não tem o mesmo peso que a reflexividade sobre a agência dos sujeitos devido à intensidade das mudanças na vida contemporânea. A descontinuidade contextual gera um "imperativo reflexivo" e, portanto, o incremento da morfogênese.

No lugar das diretrizes habituais, os sujeitos tornam-se cada vez mais dependentes das preocupaçôes pessoais, os únicas guias da ação. A deliberação reflexiva é cada vez mais inescapável para se adotar um curso de ação capaz de realização: autointerrogação, automonitoramento e autorrevisão passam a ser necessários, tendo em vista que cada um é alçado à condição de seu próprio guia (Archer, 2011, p. 177). 
Archer desenvolve a tipificação da reflexividade em quatro níveis: reflexividade comunicativa, reflexividade autônoma, metarreflexividade e reflexividade fraturada.

A primeira refere-se à reflexividade desenvolvida em relação aos pares, ou seja, as conversas internas são mediadas (confirmadas ou ajustadas) pela rede social mais próxima, como a família e os amigos, e tendem a ser morfoestáticas.

A reflexividade autônoma diz respeito às ações desenvolvidas com mais autonomia, sendo as conversaçôes internas mais orientadas segundo os projetos pessoais do que as relaçóes interpessoais, ou seja, as açôes resultantes desse tipo de reflexividade tenderiam a ser mais morfogênicas.

A metarreflexividade, por sua vez, seria um tipo de reflexividade mais crítica das açôes e do contexto (condicionalidades estruturais e culturais) do sujeito e, portanto, uma reflexividade autocrítica.

Por fim, a reflexividade fraturada refere-se às açōes dos sujeitos em que as conversaçōes internas não conduzem a uma deliberação coesa (ou clara), mas a uma desorientação pessoal sobre como agir em relação às condicionantes estruturais e culturais.

Segundo Caetano (2013, p. 83), o que essa tipologia permite perceber é que

as diferenças encontradas entre os modos de reflexividade resultam da interação entre pessoas e estruturas, preocupações e contextos. Significa, portanto, que a concretização de alguns projetos depende mais dos contextos sociais do que outros, e que os sujeitos definem quanto de si mesmos investem na ordem social.

Archer criticou a teoria da estruturação, a confusão entre a realidade social e o individual, tendo desenvolvido essa distinção e explorado a interação entre ambas. Mas, ainda que, em Giddens, o conceito de estrutura seja problemático, sobrepondo o sistema à agência individual, também na abordagem dele a estrutura social é irredutível ao individual, sendo reproduzida e modificada pela ação individual condicionada (King, 2010). King revê a trajetória intelectual de ambos os autores, classificando-os de semelhantes. Ambos se encaminharam para a libertação do indivíduo em relação às constantes estruturais. 
Archer and Giddens have traversed a similar trajectory. From an original advocacy of ontological dualism, in which structural conditions seem to have been given the primary weight, they have moved to the other dimension and now priorize the autonomous self (King, 2010, pp. 257-8).

\section{Os interacionistas: a trama do social}

Nos Estados Unidos, desde o início do século XX, Herbert Blumer, Howard Becker, Erving Goffman, entre muitos outros, introduziram a visão do fenômeno social como um processo que se constrói na dinâmica das interações face a face. Essas interaçooes é que constituem a trama do social, num processo de influências recíprocas entre os atores, regulado por rituais e em torno de uma estratégia comum.

A teoria interacionista perspectivou-se numa leitura microssociológica da realidade e não discutiu suas implicações para o debate entre sistema social - indivíduo, ou estrutura - e agência, como o vemos hoje. O sistema social é encarado na generalidade das condiçôes sociais que facilitam ou entravam o processo e nas reaçôes dos outros, processos de controle que expressam as normas instituídas. Goffman desenvolve a ideia de representação que dá à individualidade o significado de expressão do particular no universal. É na mediação do público (os outros), no acordo que dá à ação enquanto decorre, que se substancializa o eu. $\mathrm{O}$ interacionismo simbólico apresenta, assim, um eu que é obra coletiva produzida nas interações em que se jogam normas e resistências a elas, reproduções, mas, sobretudo, reformulaçóes pelos atores implicados.

Essa perspectiva do eu como agência coletiva de reaçôes de feedback está necessariamente implicada no debate sobre a reflexividade, desde logo pelo questionamento do grau de consciência (no sentido de conhecimento presente à consciência no espaço-tempo da ação, sentido a que se refere a noção de reflexividade, para além da consciência de estar a agir) envolvido nas interações (Giddens, 2003).

Nessa perspetiva microssociológica de análise das interações, Randall Collins (2009) explora a noção de rituais, partindo de Durkheim e Bourdieu. Os rituais é que produzem o social nos encontros localmente situados, pelo que a compreensão de como funciona a estrutura exige a especificação detalhada dos mecanismos localizados que a constituem. As ideias e as crenças não se explicam por si mesmas, emergindo das práticas sociais. 
O desenvolvimento de Collins sobre as interações rituais interessa a esta revisão de conceitos em torno da questão da reflexividade particularmente por causa da atenção que dispensa à emoção como energia motivadora para a ação. Em sua definição, o ritual produz uma realidade partilhada através do "mecanismo de focagem simultânea da atenção e da emoção" (Collins, 2009, p. 21). O efeito dos rituais consiste em dar significado e recarregar de sentimento os objetos simbólicos socialmente valorizados e constituintes da moralidade, como observa Durkheim. E o ritual que se rompe gera incômodo moral, já assinalava Goffman (Collins, 2009, p. 45).

\section{Pierre Bourdieu: estruturalismo construtivista}

A reflexividade na abordagem praxiológica de Bourdieu dialoga com as condições sociais de possibilidade na realidade objetiva, partindo do princípio de que o sujeito se reapropria de si mesmo de forma reflexiva na prática, como um produto social dessas condiçôes. O gosto, por exemplo, que nada tem a ver com dom, é agência dessa reapropriação reflexiva, exercendo-se num leque de possibilidades enquadradas pelo habitus (Bourdieu, 1979). Caso contrário, seria a abordagem da arte pela arte, despolitizada, como um estado puro e distanciado dos esquemas de percepção que desenvolvemos no curso da história social: não olhamos os quadros, ou escolhemos comer frutas, legumes e verduras, por nós mesmos; o que fazemos é atualizar nossa sensibilidade nas condiçôes sociais de nosso tempo, a fim de realizar nossos julgamentos. É difícil interrogar sobre o gosto, pois o julgamento do gosto julga a nós mesmos. Atribuir distinção ao comer saudável é como um reflexo da inserção social por meio de instituições como escola, família e igreja.

O espaço social engendra um conjunto de campos produzidos pela divisão social do trabalho, relativamente autônomos e homogêneos, que dizem respeito a uma função social de produção de recursos materiais e culturais. Esses recursos ou capitais são de tipo econômico, cultural, social ou simbólico, definindo-se, por seu volume e pela relação entre eles, a posiçãao dos agentes no espaço social. Existir no espaço social implica participar de um jogo social e cultural de distinção, de marcação de distâncias em relação aos outros, jogo que estrutura a identidade social de cada agente e que, muito lentamente, está na base da mudança social (Bourdieu, 1979). 
Tomando, entre outros, a alimentação como um campo em que os agentes disputam posições entre dominantes e dominados, bem como seus matizes e desdobramentos, configura-se um princípio de organização, tal como ocorre em todos os campos do social. A posição social de um agente no campo é condicionada (particularmente) pela origem social e pela instrução, e condicionadora das disposições mentais - o habitus - que orientam as preferências e as práticas culturais. Por meio da socialização, o indivíduo interioriza as atitudes, os valores e as representações que o levam a perceber o mundo e nele agir de acordo com sua classe social (grupo definido pela posição no espaço social). Nesse sentido, o habitus é a forma incorporada da condição de classe ou, na expressão de Bourdieu, é o "ter" transformado em "ser". O indivíduo e o social são concepções intimamente relacionadas, mediadas pelo habitus como "disposições" associadas à cultura, na forma de esquemas de percepção e de ação partilhados pelos indivíduos de uma mesma classe (ou fração de classe).

O habitus é uma espécie de sentido prático das coisas, uma capacidade de improvisação estruturada no jogo social de distinção (à semelhança das regras de gramática, que, apesar de seu carácter estruturado, permitem a linguagem numa diversidade indefinida). No jogo social possibilitado pelo habitus, não há uma simples execução das normas, mas uma aptidão (competência e disposição), há uma "gramática” para agir e orientar-se de determinada forma, sem se recorrer à reflexão consciente (Bourdieu, 1979).

$\mathrm{Na}$ leitura de Bourdieu, as disposições são consolidadas de forma duradoura e atuam de modo sistemático em todas as práticas. São, ao mesmo tempo, estruturadas (a tendência conservadora no sentido de inércia) e estruturantes (o princípio de mudança no sentido da individualização das trajetórias de vida). São diferenciadas (produto das posições sociais) e diferenciadoras (geradoras de práticas distintas). Ou seja, os habitus geram estilos de vida característicos das identidades sociais (gostos, crenças e práticas características de cada classe) e, dessa forma, constituem esquemas de classificação na hierarquia das diferenças simbólicas entre as classes.

A teoria da dominação de Bourdieu mostra que as relaçóes sociais não são só relações de força, mas também relações de sentido. Elas impõem significados que dissimulam as relaçôes de força. Um poder simbólico de imposição das categorias de percepção do mundo social é a base para a dominação que constitui e mantém as estruturas de poder. É pela cultura na forma de 
disposições incorporadas (valores, normas e práticas) diferenciadoras dos estilos de vida (maneiras de sentir, pensar e fazer) e associadas a um poder simbólico (sistema de significados hierarquizados que diferenciam os estatutos sociais) que os dominantes garantem sua dominação. Bourdieu (1979) explica como a violência simbólica é exercida sobre o agente social com sua cumplicidade, levando a dominação a ser aceita como legítima, na medida em que transforma em cultura legítima a visão do mundo que está em consonância com os interesses da classe dominante.

\section{Bernard Lahire: o indivíduo plural}

Bernard Lahire $(2002,2005)$ desenvolve e aprofunda o conceito de disposiçōes, no sentido de explicar sua constituição social e as respectivas modalidades de atualização. Sua reflexão orienta-se por perceber os processos pelos quais a realidade exterior é incorporada (no sentido de se tornar corpo), por como convivem no mesmo corpo experiências socializadoras múltiplas e por como essa heterogeneidade intervém nos diferentes momentos da vida social ou da biografia de um indivíduo. Vai além de afirmar a existência das disposiçôes, deduzida da análise das práticas, e procura os mecanismos pelos quais essas práticas são ativadas ou suspensas, segundo os domínios ou os contextos da vida social. Propõe, por exemplo, a distinção entre as disposiçôes para agir e para crer (ou crenças). Chama a atenção para o fato de que as disposiçōes se constituem a partir das normas sociais produzidas, suportadas e difundidas pelas instituições (família, escola, igreja etc.) e são mais ou menos confirmadas pela experiência do cotidiano. As disposições apresentam diferentes graus de fixação e de força, o que depende de sua constituição (aprendizagem), mas também da recorrência de sua atualização posterior (sobreaprendizagem).

Esse autor também chama a atenção para o caráter generalizável dos esquemas ou disposições socialmente constituídas. A transferibilidade do habitus, como definida por Bourdieu, deve ser pensada em relação com os contextos e as áreas de pertinência e atualização das disposiçōes. Lahire (2005) desdobra o conceito de habitus ao distinguir entre as diversas modalidades de incorporação de hábitos que estão na base do conceito que o autor aplica às análises, nomeadamente a diferenciação entre disposição (propensões, inclinaçōes) e apetência para agir. Dessa forma, as disposições para crer não 
seriam sistematicamente assimiladas às disposições para agir, na medida em que os atores podem incorporar crenças sem dispor dos meios para cumprilas - defasagem entre crenças e condições objetivas - ou podem interiorizar modelos de comportamento sem adquirir os hábitos de colocá-los em prática - defasagem entre crenças e disposições para agir.

Em sua singularidade, o indivíduo é feito de pluralidade interna, portador de hábitos que, em alguns casos, têm sentido oposto em relação às suas próprias crenças, razão pela qual, segundo esse autor, torna-se mais adequado encarar as disposiçóes como um patrimônio (stock) de disposições heterogêneas, de modalidades e forças distintas, com diferentes aptidões para impelir à ação e à autoconsciência reflexiva.

Em outro momento, caberia, portanto, aprofundar como as coisas triviais e costumeiras operam uma "intencionalidade sem intenção" nas brechas quando da reprodução das regularidades, como as diferenças plurais no indivíduo de Lahire podem ser sistematizadas na composição dos esquemas de percepção da sociedade ou como povoam os esquemas de previsibilidade das posições de classe.

\section{Retomando a questão de partida}

Esta revisão dos principais conceitos e teorizações do pensamento sociológico sobre reflexividade apresenta a vantagem de clarificar as perspectivas mais importantes sobre a agência individual, necessariamente reflexiva, do indivíduo moderno. Retoma-se agora a questão de partida, sobre a reflexividade nas práticas alimentares, "O que as pessoas sabem e como usam o que sabem?, recorrendo-se aos contributos daquelas teorias.

O corpo está no centro do imperativo de construção reflexiva da identidade, objeto e alvo do poder de adestramento no sentido da docilidade, sujeito à vigilância da disciplina (Foucault, 1975). Foucault (1976) teorizou a construção do indivíduo na modernidade como a incorporação do conhecimento na política e na vida (o biopoder), por meio de disposições concretas que investem o corpo, a saúde, a alimentação e todo o espaço de existência. O indivíduo da modernidade, objetivado pela ciência, tornou-se um sujeito dotado de autoconsciência regulada pelos discursos fundamentados no "saber, conhecimento e ciência”.

Com efeito, os estudos empíricos que temos realizado constatam que a vida moderna integrou o "dever de saúde" como responsabilidade do 
indivíduo (Herzlich, 1969). O "dever de saúde" refere-se ao conhecimento da normatividade médica, em relação ao que é saudável, bem como à preocupação de autocontrole no respeito pelas normas, no que representa uma manifestação do biopoder. Nele, integra-se a alimentação "saudável", como um de seus componentes fundamentais.

Mas, se a submissão do indivíduo ao discurso dominante sobre a alimentação saudável e suas normas se verifica no nível do pensamento e do discurso público, o mesmo não acontece no que diz respeito à submissão das práticas às normas. Os estudos empíricos têm mostrado que, apesar de haver um conhecimento generalizado sobre a necessidade de haver responsabilidade pessoal pela saúde e uma concordância declarada com as normas do que é "saudável", na prática os comportamentos não revelam essa consonância (Calnan, 1990; Blaxter, 1998; Ziglio et al., 2000).

Alguns estudos empíricos também revelam que é generalizado o conhecimento sobre os riscos alimentares, sejam aqueles configurados pela nutrição, em torno do que é saudável, sejam os relativos a acidentes imprevistos no campo da industrialização ou da comercialização (por exemplo, o caso das "vacas loucas", do frango com dioxinas etc.) (Silva, 2008). Ou seja, a reflexividade relativa do conhecimento sobre "o que é saudável" está presente no pensamento individual sob a forma de conhecimento. Mas em que medida influencia a agência individual?

Em Giddens, Beck e Archer, a agência individual está para além do monitoramento da ação, característica da ação humana consciente. O que está em causa no uso desse conceito não é a mera consciência de estar a agir ou a decisão consciente de como agir. A reflexividade é o conceito que, na capacidade de reflexão sobre a ação, integra a informação do conhecimento sobre essas mesmas práticas (Giddens, 2003). É a essa característica da modernidade - o conhecimento, sua divulgação generalizada e sua mudança contínua - que a reflexividade se refere como implicação da agência individual. Mas, se a reflexividade presente na consciência não se converte em agência racionalmente consequente com o próprio conhecimento, é necessário interrogar os processos que se fazem presentes em sua capacidade de influenciar a agência individual.

$\mathrm{Na}$ base da agência reflexiva, está a multiplicidade de oportunidades, a qual, por sua vez, cria ambivalência e obriga o indivíduo a escolher, a avaliar os riscos, a tomar decisões (Beck, 2011). Nesse processo, Beck alerta para a implicação da especificidade cultural. E Archer indica a sequência 
morfogenética básica e suas três fases. Com efeito, esses são processos sociais que, nas pesquisas empíricas, aparecem implicados nas "conversações internas" dos indivíduos em matéria de alimentação saudável.

Em uma pesquisa efetuada sobre o saber leigo de saúde (Silva, 2008), verificou-se que o contexto cultural e relacional é frequentemente convocado como justificativa para as opçóes práticas. A região em que se vive "tem carne muito boa", por exemplo, justifica o consumo quase exclusivo de carne como alimento animal, embora se afirme que "é aconselhável comer mais peixe", assim como a partilha com familiares e amigos pressiona no sentido de práticas de consumo alimentar "nocivas". A reflexividade torna-se explícita nos discursos quando os indivíduos se referem a situações de interação social que fazem apelo a ajustes recíprocos dos atores, nomeadamente quando estão em causa os rituais de interação (por exemplo, "o chocolatinho com o café"). Desse ponto de vista, a interrogação acerca da influência da reflexividade na agência individual remete para as teorias interacionistas e para sua atualização por Collins (2009).

Em um estudo realizado com jovens graduandos de nutrição e educação física (Castro et al., 2015), observou-se tensão interna no discurso biomédico do saudável e do comedimento, reiterando-se o discurso de um lado e reagindo do outro - ora reproduzindo-o com o sentido de distinção social que os capitaliza, ora tomando-o como uma referência ao contrário, da qual os jovens divergem para favorecer uma adequação ao ethos do grupo social, ora ainda em um movimento de aproximação, ora de afastamento. Isso nos conduz a outra abordagem sobre o habitus de Bourdieu, articulando a singularidade do sujeito e a pluralidade da cultura contemporânea debatida por Bernard Lahire sobre as pequenas reflexividades, levando-se em conta que o conhecimento praxiológico se especializa na prática em condiçóes muito particulares, com agentes que se encontram posicionados externamente aos jogos de prestígio e dominação, fora do campo de forças. Haveria, portanto, um indivíduo plural com inferência singular na prática que pode ser pensada como atípica, que escapa à cumplicidade da relação de forças do campo.

A pesquisa empírica também remete para Archer (2005) e Bourdieu (1979) se forem levadas em consideração as condicionantes estruturais enunciadas a propósito das dificuldades de se optar por uma alimentação saudável, condicionantes de tempo, acessibilidade e custo econômico (para fazer a refeição da hora do almoço, ou para realizar as compras de alimentos, por exemplo). 
Em outra investigação, homens idosos que moram sozinhos atualizam o significado do que é saudável, segundo as condiçōes de aposentadoria, viuvez e saída dos filhos de casa, quanto à alimentação fora do lar:

O comer fora de casa assume um sentido de socialização, representando uma inclusão no mundo globalizado. Frequentar praças de alimentação nesse contexto, especialmente quando se está sem companhia, se mostrou mais interessante para os idosos do que despender tempo na cozinha para o preparo de uma refeição que não seria compartilhada. Tanto comer fora quanto comprar comida fora para comer em casa motivaram novos tipos de relacionamentos sociais nessa população (Cavalcante et al., 2015).

Ainda nessa perspectiva, intencionalmente ou não, a reflexividade é uma forma de apropriação de si mesmo no caso de mulheres idosas na Universidade Aberta da Terceira Idade da Universidade do Estado do Rio de Janeiro, em que a praticidade surge como determinante na alimentação desses idosos, que, conectados ao ritmo de vida moderno, "não têm tempo a perder". Há um consenso no grupo de que é preciso aprender a se alimentar na idade avançada, em busca de um equilíbrio entre as descobertas científicas em prol da longevidade, as exigências do mundo moderno, o envelhecimento do corpo e os prazeres da vida (Kuwae et al., 2015).

Archer defende que, na agência dos sujeitos, a reflexividade se sobrepõe à socialização devido à intensidade das mudanças na vida contemporânea. Os estudos empíricos encontram muitas situações em que esse fato se confirma, especialmente nas camadas mais jovens, nos meios urbanos e profissionalizados (a chamada alimentação mediterrânea, ainda habitual nas pessoas com mais idade e praticamente desaparecida do cotidiano das pessoas mais jovens, que, precisamente, referem só comer "com sopinha e tudo" na casa "da mãe", no almoço de domingo) (Silva, 2008). No entanto, outras situações demonstram o peso da socialização, superior ao da reflexividade do conhecimento, como aquelas em que o tipo de cozinha condenada de forma discursiva (frituras, por exemplo) é praticado devido à aprendizagem socializada da tradição. Os valores da tradição (tomar sopa e comer legumes cozidos em vez de saladas, por exemplo) e os ideais da modernidade (comprar comida pré-preparada e produtos valorizados pela mídia, por exemplo), aliás, podem ser convocados pelos mesmos indivíduos, de acordo com o 
tipo de situação. Para além das condicionantes objetivas, está onipresente o gosto, essa condicionante subjetiva que os grupos sociais transmitem em seu interior, associada à posição de classe. Como afirma Bourdieu, é “o gosto”, esse fator aparentemente apenas pessoal e não condicionado, que orienta as escolhas dos atores.

No conjunto, os resultados da pesquisa empírica orientam para a complexidade das relações entre reflexividade e agência individual, apelando para as observações teóricas que procuram decifrá-las. Em Archer, a reflexividade pode ter mais ou menos peso na agência, de acordo com as formas de conhecimento (incorporado, prático e discursivo) e suas ordens da realidade (natural, prática e social) (Archer, 2011). Também nessa autora, encontra-se uma tipificação da reflexividade em reflexividade comunicativa, reflexividade autônoma, metarreflexividade e reflexividade fraturada, em relação com a interação entre pessoas e estruturas, preocupaçōes e contextos (Caetano, 2013). Por sua vez, Lahire chama a atenção para a pluralidade das disposições e condições de sua atualização, distinguindo entre as disposições para crer e as disposições para agir (Lahire, 2005).

Mas pensar a reflexividade e sua capacidade de impregnar a agência individual está para além dos processos relacionais em que se manifesta a relação entre ambas. Os estudos empíricos que vimos realizando apontam o caminho da procura de compreensão sobre como é constituída, em si mesma, a reflexividade no saber leigo. Ou seja, não interessa conhecer o "como decide o indivíduo com o conhecimento de que dispõe" sem antes perceber "de que conhecimento(s) dispõe".

Quando a ciência social trata da reflexividade institucional e da reflexividade do conhecimento como imperativo moderno, subentende-se a impregnação do social pelo saber moderno, saber que tem por base hegemônica a ciência e que é divulgado massivamente pelos meios de comunicação social e pelas instituições (no caso do saudável, nomeadamente a instituição de saúde). Mas, entre o saber dos peritos, consagrado e disseminado, e o saber que se constitui como saber leigo, há uma grande distância, feita, em grande parte, de saberes que se contradizem. O pensamento leigo assimila a informação por processos não lineares, de simples absorção, mas complexos, integrando o novo conhecimento com conhecimentos anteriores, muitos de natureza não científica, cultural, ou seja, subjetiva. 
A questão crucial da lógica do saber leigo e da racionalidade dos seus comportamentos é que nem todos os seus elementos constitutivos são associados de acordo com a lógica formal da ciência, estando imbuídos de considerações afectivas, tendo por função interpretar a experiência. Ele é um saber prático, não metódico, fundado sobre racionalidades distintas da racionalidade linear científica. [...] Saber leigo é o conjunto de conhecimentos - no sentido amplo, que inclui as representações sociais com todos os seus elementos valorativos, ideológicos etc. (Silva e Alves, 2011, p. 1.219).

Vários autores têm investigado a racionalidade do pensamento comum, demonstrando que não é irracional ou "a-racional”, mas se refere a uma racionalidade "outra" que não a da ciência, linear, metódica e sistemática. Moscovici (1961) propôs o conceito de polifasia cognitiva para dar conta da diversidade do saber e das diferenças entre lógica e racionalidade (das crenças) que vários antropólogos já haviam enfatizado. Raymond Boudon (2009) analisou a racionalidade do pensamento comum, apresentando-o como contextual e expressiva. Sob a perspetiva da sociologia da ciência, Santos (2004) evidencia a presença de racionalidades plurais e de uma pluralidade de conhecimentos de que a ciência é apenas uma forma (de conhecimento).

A reflexividade do conhecimento em matéria do que é "saudável” resulta, no pensamento individual, como uma configuração feita de relações múltiplas e interdependentes entre conhecimentos plurais, em que a racionalidade científica aparentemente se submete à racionalidade cultural, a qual usa representações sociais, valores, ideais, emoções e experiência. É principalmente nessa perspectiva que será possível alcançar o aprofundamento da compreensão do que é saudável nas práticas cotidianas.

\section{Referências}

ARCHER, M. Realist social theory: the morphogenetic approach. Cambridge: Cambridge University Press, 1995.

. "Habitus, reflexividade e realismo". Dados: Revista de Ciências Sociais, Rio de Janeiro, v. 54, n. 1, 2011, pp. 157-206.

AZEVEDO, E. "Reflexões sobre riscos e o papel da ciência na construção do conceito de alimentação saudável”. Revista de Nutrição, v. 21, n. 6, 2008, pp. 717-23.

BECK, U. "A reinvenção da política". In — et al. (orgs.). Modernização reflexiva: política, tradição e estética na ordem social moderna. Oeiras: Celta, 2000, pp. 1-52. 
. Sociedade de risco: rumo a uma outra modernidade. São Paulo: Editora 34, 2011.

BLAXTER, M. Health and lifestyles. Londres: Routledge, 1998.

BOUDON R. La rationalité. Paris: PUF, 2009.

BOURDIEU, P. La distinction: critique sociale du jugement. Paris: Édition de Minuit, 1979. CAETANO, A. Vidas reflectidas: sentidos, mecanismos e efeitos da reflexividade individual (tese). ISCTE-IUL, Lisboa, 2013.

CALNAN, M. "Food and health: a comparison of beliefs and practices in middle-class and working-class housebolds”. In CUNNIGHAM-BURLEY, S. Readings in Medical Sociology. Londres: Routledge, 1990, pp. 269-86.

CANCLINI, N. G. A globalização imaginada. São Paulo: Iluminuras, 2007.

CARVALHO, M. C. V. S. e SABINO, C. "Comida natural: o consumo neorromântico da roça visto da cidade grande”. In PRADO, S. D et al. (orgs.). Sabor metrópole: alimentação, consumo e cultura. Curitiba: CRV, 2013, pp. 15-30.

CASTIEL, L. D. Correndo o risco: uma introdução aos riscos em saúde. Rio de Janeiro: Fiocruz, 2010.

CASTRO, J. B. P. et al. "Faça o que eu digo, mas não faça o que eu faço!: a décalage como ferramenta para a compreensão de práticas corporais e alimentares”. Revista de Nutrição, Campinas, v. 28, n. 1, 2015, pp. 99-108.

CAVALCANTE, C. M. S. et al. "Sentidos da alimentação fora do lar para homens idosos que moram sozinhos". Revista Brasileira de Geriatria e Gerontologia, Rio de Janeiro, v. 18, n. 3, 2015, pp. 611-20.

CHAUÍ, M. Convite à filosofia. São Paulo: Ática, 2000.

COLLINS, R. Cadenas de rituales de interacción. Barcelona: Anthropos, 2009.

CONTRERAS, J. e GRACIA, M. Alimentação, sociedade e cultura. Rio de Janeiro: Fiocruz, 2011.

COSTA, M. et al. "Dietas da moda: um processo incessante e ininterrupto". In PRADO, S. D et al. (orgs). Sabor metrópole: alimentação, consumo e cultura. Curitiba: CRV, 2013, pp. 103-21.

FERREIRA, F. R et al. "O culto ao corpo, a estetização da saúde e o papel do nutricionista". In PRADO, S. D. et al. (orgs.). Sabor metrópole: alimentação, consumo e cultura. Curitiba: CRV, 2013, pp. 87-102.

FISCHLER, C. El (h)omnivero: el gusto, la cocina y el cuerpo. Barcelona: Enagrama, 1995.

FOUCAULT, M. Surveiller et punir. Paris: Gallimard, 1975. . La volonté de savoir: histoire de la sexualité 1. Paris: Gallimard, 1976.

FREIRE, G. B. et al. "Sequei $40 \mathrm{Kg}$ com a bala que emagrece: medicalização da comida em capas de revistas femininas". In FREITAS, R. F. et al. (orgs.). Sabor metrópole: corpo e consumo nas cidades. Curitiba: CRV, 2014, pp. 27-46.

GALINDO, F. e PORTILHO, F. "Crises alimentares: repercussão na mídia e reação de consumidores”. In PRADO, S. D. et al. (orgs.). Sabor metrópole: alimentação, consumo e cultura. Curitiba: CRV, 2013, pp. 213-36.

GARDNER, D. Risco: a ciência e a politica do medo. Rio de Janeiro: Odisseia, 2009.

GIDDENS, A. Transformação da intimidade: sexualidade, amor e erotismo nas sociedades modernas. São Paulo: Unesp, 1993. 
. "Viver numa sociedade pós-tradicional". In BECK, U. et al. (orgs.). Modernização reflexiva: política, tradição e estética na ordem social moderna. Oeiras: Celta Editora, 2000, pp. 53-104.

. Modernidade e identidade. Rio de Janeiro: Zahar, 2002.

. A constituição da sociedade. São Paulo: Martins Fontes, 2003.

HERZLICH, C. "Santé et maladie: analyse d'une représentation sociale". Annales. Économies, Sociétés, Civilisations, Paris, v. 24, n. 6, 1969, pp. 1.519-21.

KING, A. "The odd couple: Margaret Archer, Anthony Giddens and British social theory". The British Journal of Sociology, Londres, v. 61, sup. 1, 2010, pp. 253-60.

KUWAE, C. A. et al. "Concepções de alimentação saudável entre idosos na Universidade Aberta da Terceira Idade da UERJ: normas nutricionais, normas do corpo e normas do cotidiano". Revista Brasileira de Geriatria e Gerontologia, Rio de Janeiro, v. 18, n. 3, 2015, pp. 621-30.

LAHIRE, B. O homem plural: os determinantes da ação. Petrópolis: Vozes, 2002.

. "Patrimónios Individuais de Disposiçôes: para uma sociologia à escala individual". Sociologia, Problemas e Práticas, Lisboa, n. 49, 2005, pp. 11-42.

LUPTON, D. A. e CHAPMAN, S. "A healthy lifestyle might be the death of you: discourses on diet, cholesterol control and heart disease in the press and among the lay public". Sociology of Health \& Illness, Leeds, v. 17, n. 4, 1995, pp. 477-94.

MENNEL, S. et al. The sociology of food: eating, diet and culture. Londres: Sage Publication, 1992.

MINTZ, S. “Comida e antropologia: uma breve revisão”. Revista Brasileira de Ciências Sociais, São Paulo, v. 16, n. 47, 2001, pp. 31-42.

MOSCOVICI, S. La psychanalyse, son image, son public. Paris: Presses Universitaires, 1961.

PORPORA, D. V. "Morphogenesis and Social Change". In ARCHER, M. S. (org.). Social morphogenesis. Berlim, 2013, pp. 25-37.

SANTOS, B. S. Semear outras soluçôes: os caminhos da biodiversidade e dos conhecimentos rivais. Porto: Afrontamento, 2004.

SILVA, L. F. "A saúde e o saudável nas racionalidades leigas: o caso da alimentação". In CARAPINHEIRO, G. e MENDES, F. Sociologia da saúde: estudos e perspectivas. Lisboa: Pé de Página, 2006, pp. 165-95.

. Saber prático de saúde: as lógicas do saudável no quotidiano. Porto: Afrontamento, 2008. e ALVES, F. “Compreender as racionalidades leigas sobre saúde e doença”. Physis, Rio de Janeiro, v. 21, n. 4, 2011, pp. 1.207-29.

ZIGLIO, E. et al. "Health promotion development in Europe: achievements and challenges". Health Promotion International, n. 15, v. 2, 2000, pp. 143-54. 